\title{
ANALISIS KALIMAT IMPERATIF DALAM VIDEO TUTORIAL SKINCARE CLARIN HAYES DI YOUTUBE DAN RELEVANSINYA PADA PEMBELAJARAN TEKS PROSEDUR DI SMA
}

\author{
Anak Agung SriDarmawanti ${ }^{1}$, Made Sri Indriani ${ }^{2}$, Made Astika ${ }^{3}$ \\ Prodi Pendidikan Bahasa Indonesia, Jurusan Bahasa Sastra Indonesia dan \\ Daerah, Fakultas Bahasa dan Seni, Universitas Pendidikan Ganesha \\ Singaraja, Indonesia \\ e-mail:gungsri057@gmail.com¹, \\ sriindriani6114@gmail.com ${ }^{2}, \underline{\text { made.astika@undiksha.ac.id }}{ }^{3}$
}

\begin{abstract}
ABSTRAK
Penelitian ini bertujuan (1) untuk mendeskripsikan kalimat imperatif dalam video tutorial skincare Clarin Hayes di Youtube, dan (2) untuk mendeskripsikan kesesuaian video tutorial skincare Clarin Hayes di Youtube sebagai bahan ajar teks prosedur di SMA. Penelitian ini menggunakan metode deskriptif kualitatif. Analisis data dilakukan dengan teknik analisi deskriptif kualitatif. Hasil penelitian menunjukkan bahwa: (1) video tutorial skincare Clarin Hayes menggunakan lima macam kalimat imperatif; kalimat imperatif permintaan paling banyak digunakan dalam video tutorial skincare Clarin Hayes; yang terdiri atas 9 kalimat imperatif biasa, 23 kalimat imperatif permintaan, 5 kalimat imperatif pemberian izin, 9 kalimat imperatif ajakan, dan 15 kalimat imperatif suruhan; (2) video tutorial skincare Clarin Hayes memiliki relevansi dengan pembelajaran teks prosedur di SMA; video tutorial Skincare Clarin Hayes memiliki struktur dan syarat sesuai dengan pembelajaran teks prosedur, semua struktur dan kaidah kebahasan dalam teks prosedur; terdapat dalam video tutorial skincare Clarin Hayes hanya saja menggunakan gaya bahasa nonbaku.
\end{abstract}

Kata Kunci: Kalimat Imperatif,Video tutorial, Youtube 


\begin{abstract}
This study aims (1) to describe imperative sentences in the skincare video tutorial on Clarin Hayes on Youtube, and (2) to describe the suitability of skincare video tutorials on Clarin Hayes on Youtube as teaching materials for procedural texts in high school. This study used descriptive qualitative method. Data analysis was carried out by qualitative descriptive analysis techniques. The results of the study show that: (1) skincare tutorial videos Clarin Hayes uses five kinds of imperative sentences; the most used imperative sentence used in the skincare tutorial video is Clarin Hayes; consisting of 9 ordinary imperative sentences, 23 imperative sentence requests, 5 imperative sentences giving permission, 9 imperative sentences, and 15 imperative sentences; (2) Clarin Hayes skincare tutorial videos have relevance to procedure text learning in high school; Skincare video tutorials Clarin Hayes has the structure and requirements according to the procedure text learning, all the structure and rules of linguistics in the procedure text; in the skincare tutorial video Clarin Hayes only uses the nonbaku language style.
\end{abstract}

Keywords:Imperatif sentence, Video tutorial, Youtube

\section{PENDAHULUAN}

Bahasa merupakan alat komunikasi yang berperan penting dalam kehidupan manusia. Tanpa bahasa manusia tidak bisa berkomunikasi, bersosialisasi, bahkan berinteraksi. Segala sesuatu yang ingin disampaikan harus menggunakan bahasa agar pesan atau keinginan yang dikehendaki tercapai.Menurut Suwandi (2008:24), bahasa adalah sistem lambang yang bersifat arbitrer, yang dipakai oleh para anggota suatu masyarakat untuk bekerjasama, berinteraksi dan mengidentifikasi diri.Bahasa di seluruh dunia termasuk Indonesia terus mengalami perkembangan yang signifikan akibat semakin pesatnya kemajuan teknologi dan IPTEKS.

Penggunaan bahasa pun menjadi semakin luas dalam berbagai bidang baik secara lisan maupun tulis. Salah satunya penggunaan bahasa sehari-hari adalah penggunaan bahasa dalam media sosial. Menurut Cangara (2010:29), media sosial adalah label bagi teknologi digital yang memungkinkan orang untuk berhubungan, berinteraksi, memproduksi, dan berbagi isi pesan.

Media sosial Youtube tentunya tidak asing bagi sebagian orang terutama orang yang sudah mengenal media sosial. Banyak kelebihan yang diberikan Youtube, salah satunya tidak sedikit orang atau kelompok yang menjadi terkenal semenjak rajin mengunggah video miliknya di Youtube. Berdasarkan berita yang dimuat dalam tempo.com Jumat 26 Mei 2018 mengenai survei media sosial, Youtube dikatakan berdampak paling positif dibandingkan media sosial lainya.

Banyak orang membuat video melalui Youtube dan menjadi seorang vlogger bahkan youtubers. Kesuksesan seorang youtubers biasanya dilihat dari banyakanya subscribers. Salah satu yang hangat diperbincangkan di kalangan remaja yaitu vlog tentang skincare routine Clarin Hayes. Sekian banyakanya video atau vlog yang dibuat Clarin Hayes ,tutorial penggunana skincare paling banyak 
diminati dengan jumlah subcribe mencapai216rbx.

Namun, justru hal yang paling penting jarang diketahui oleh sebagian orang. Sebagian orang jarang mengetahui urutan penggunan skincare yang benar sehingga berdampak buruk pada kulit. Seberapa bagus dan mahal sebuah produk jika penggunaanya salah tentu tidak akan mendapatkan hasil sesuai dengan harapan. Oleh karena itu, pentingnya sebuah tutorial penggunaan skincare dalam penggunaanya. Berbicara tentang tutorial skincare tentunya tidak lepas dari langkah-langkah atau tahapan-tahapan didalamnya.

Tutorial tidak hanya ada dalam kehidupan sehari-hari, dalam dunia pendidikan tutorial dikenal dengan teks prosedur. Dalam tutorial dan teks prosedur memiliki aturan yaitu, adanya isi, struktur, dan unsur kebahasaan di dalamnya. Namun, tutorial juga dipengaruhi oleh kalimat yang digunakan. Kalimat yang terdapat di dalam teks prosedur biasanya berupa kalimat imperatif (perintah), kalimat persuasif (ajakan), kata teknis (mencangkup hal yang dibicarakan), konjungsi (kata penghubung), dan deskripsi alat atau bahan (Setianingsih, 2017:15). Salah satu kalimat yang ada dalam teks prosedur adalah kalimat imperatif.

Kalimat imperatif adalah kalimat yang meminta pendengar atau pembaca melakukan suatu tindakan (Chaer, 2015:197) Kalimat di dalam video tutorial skincare Clarin Hayes pun menggunakan kalimat imperatif, namun berbeda dengan kalimat imperatif pada contoh-contoh teks prosedur. Perlunya pemahaman dan ketelitian untuk melihat kalimat imperatif pada video tutorial skincare Clarin Hayes. Contoh lain pada tuturan yak yang umunya jika dalam teks prosedur adalah "selanjutnya atau kemudian".

Pentingnya penggunaan kalimat yang baik dalam teks prosedur akan mempengaruhi informasi yang disampaikan pada pendengar. Dilihat dari video tutorial skincare Clarin Hayes pentingnya pembahasan dan pemahaman tentang kalimat imperatif atau perintah yang digunakan, melihat pengguna atau subscriber dari latar belakang yang berbeda-beda menyaksikan video tutorial skincare Clarin Hayes.

Sehubungan dengan hal itu, video tutorial skincare Clarin Hayes mempunyai relevansi dengan pembelajaran di sekolah terutama teks prosedur. Dilihat dari video tutorial skincare Clarin Hayes memiliki struktur sesuai dengan pembelajaran teks prosedur. Hal tersebut dapat dilihat dari isi keseluruhan video yang memiliki syarat atau ketentuan sebuah teks prosedur. Selain itu, pembelajaran di SMA saat ini, pada kurikulum 2013 terdapat kompotensi dasar "Merancang pernyataan umum dan tahapan-tahapan dalam teks prosedur dengan organisasi yang tepat secara lisan dan tulis".

Melalui kegiatan merancang pernyataan dalam teks prosedur siswa akan mendapat pengetahuan mengenai kalimat imperatif yang muncul pada video tutorial skincare Clarin Hayes dan penggunaan kalimat merancang sebuah teks prosedur. Selain itu, siswa akan mendapat pemahaman dan contoh dalam membuat teks prosedur dengan bahasa jelas dan menarik melalui video tutorial.

Berdasarkan uraian di atas, terdapat pemikiran untuk mendeskripsikan kalimat imperatif dalam video tutorial skincare Clarin Hayes di Youtube dan relevansinya pada pembelajaran teks prosedur di SMA. 


\section{METODE PENELITIAN}

Metode pengumpulan data yang digunakan pada penelitian ini adalah metode dokumentasi. Data yang diperlukan dalam penelitian ini yaitu, kalimat imperatif dalam video tutorial skincare Clarin Hayes di Youtube dan Silabus SMA kurikulum 2013 materi teks prosedur. Pada tahap pengumpulan data, peneliti mencari video tutorial skincare Clarin Hayes melalui media Youtube.

Pengumpulan data dalam penelitian ini yaitu menggunakan teknik simak dan catat. Data yang diperoleh berupa video di Youtube. Data berupa video tersebut kemudian disimak dan isi dalam video kemudian di transkripkan. Instrumen yang digunakan berupa kartu data (instrumen terlampir). Pengumpulan data berupa silabus SMA kurikulum 2013 menggunakan metode yang sama yaitu dokumentasi dengan cara download melalui internet. Analisis data dalam penelitian ini adalah teknik analisis data deskriptif kualitatif. Yakni, menggambarkan dengan menggunakan kata-kata.

Dalam penelitian yang penulis lakukan, data yang diperoleh dianalisis dengan menempuh beberapa tahap yaitu: 1.Mengumpulkan data yang diperoleh, menyimak dan menyalin kata-kata yang ada dalam video tutorial skincare Clarin Hayes di Youtube, membaca secara cermat setiap data yang diperoleh, dan menganalisis rumusan masalah pertama. Setiap data diberikan kode data untuk memudahkan dalam mengelompokanya, selanjutnya menentukan jenis kalimat, penanda dan dilengkapi keterangan kalimat imperatif dalam Video tutorial skincare Clarin Hayes di Youtube sesuai table.

Membahas permasalahan kedua mengenai relevansi video tutorial skincare Clarin Hayes pada pembelajaran teks prosedur di SMA. Mencocokan dan melihat kesesuaian isi video tutorial Skincare Clarin Hayes dengan silabus SMA kurikulum 2013 materi teks prosedur. mengelompokan data menjadi dua kelompok yaitu: kalimat imperatif dan relevansi video tutorial skincare Clarin Hayes dengan pembelajaran teks prosedur, memaparkan hasil analisis data, dan menyimpulkan hasil analisis data.

\section{HASIL PENELITIAN}

Berdasarkan data kalimat imperatif dalam video tutorial skincare Clarin Hayes diperoleh melalui media Youtube dengan menggunakan metode dokumentasi. Peneliti men-donlowd video, kemudian digunakan teknik simak dan catat untuk menyalin data berupa kalimat dalam video tutorial skincare Clarin Hayes. Data kalimat dalam video tutorial skincare Clarin Hayes diperoleh sebanyak 125 kalimat.

Data 125 kalimat ini berisi 61 kalimat imperatif yang digunakan dalam video tutorial skincare Clarin Hayes di Youtube. Data 125 kalimat ini kemudian di tulis di kolom analisis data yang berisi kode data, kalimat imperatif, jenis kalimat, penanda dan keterangan untuk memudahkan analisis data. Berdasarkan analisis data kalimat imperatif diperoleh 61 data berupa kalimat imperatif yang terdiri atas 9 kalimat imperatif biasa, 23 kalimat imperatif permintaan, 5 kalimat imperatif pemberian izin, 9 kalimat imperatif ajakan, dan 15 kalimat imperatif suruhan.

Pembelajaran teks prosedur tercantum pada silabus bahasa indonesia SMA kurikulum 2013. Pada silabus kurikulum 2013 terdapat materi teks prosedur yang harus dipahami siswa. Pembelajaran teks prosedur lebih banyak membahas tentang struktur dan kebahasaan teks prosedur. Pembelajaran teks prosedur memiliki 
kesesuaian dengan video tutorial skincare Clarin Hayes di Youtube berdasarkan isi video.

\section{PEMBAHASAN}

Berdasarkan hasil penelitian ditemukan lima macam kalimat imperatif yang digunakan dalam video tutorial skincare Clarin Hayes di youtube. Video tutorial skincare Clarin Hayes berisi 61 kalimat imperatif yang terdiri atas 9 kalimat imperatif biasa, 23 Kalimat imperatif permintaan, 5 kalimat imperatif pemberian izin, 9 kalimat imperatif ajakan, dan 15 kalimat imperatif suruhan.

Berdasarkan hasil penelitian diperoleh lima macam kalimat imperatif. Ramlan (2005:79) menyatakan bahwa macammacam kalimat imperatif yaitu: kalimat imperatif biasa, kalimat imperatif permintaan, kalimat imperatif pemberian izin, kalimat imperatif ajakan, dan kalimat imperatif suruhan. Semua macam kalimat imperatif ditemukan dalam penelitian ini. Penggunaan kalimat imperatif permintaan yang paling banyak terdapat pada video tutorial skincare Clarin Hayes di youtube, yaitu sebanyak 23 kalimat dibandingkan imperatif biasa, imperatif pemberian izin, imperatif ajakan, dan imperatif suruhan.

Hal tersebut sesuai dengan hasil penelitian Astutik (2015) yang menyatakan bahwa jenis kalimat imperatif yang ditemukan pada ceramah Ustaz Maulana ada sebanyak lima jenis kalimat imperatif yaitu: kalimat imperatif biasa, kalimat imperatif permintaan, kalimat imperatif pemberian izin, kalimat imperatif suruhan dan kalimat imperatif larangan/permintaan. Kalimat imperatif larangan dan permintaan memiliki definisi dan penegas yang sama hanya saja beberapa orang menyatakan dengan istilah larangan atau permintaan.

Begitupun dengan hasil

penelitian Candra (2015) yang menyatakan kalimat imperatif yang terdapat pada Bahasa Pembina Upacara di SMA Negeri 3 Kota Tanjungpinang meliputi kalimat imperatif sebenarnya, kalimat imperatif persilahaan, kalimat imperatif ajakan, dan kalimat imperatif larangan.Sebutan kalimat imperatif dan kalimat perintah memiliki definisi yang sama, hanya saja selama inisering disebut kalimat perintah atau kalimat seru.

Penelitian Faizatul (2016)

menemukan sepuluh kalimat imperatif pada pengajaran guru perempuan di MAN 1 Bandar Lampung tahun pelajaran 2016/2017, yaitu (1) perintah, (2) suruhan, (3) permintaan, (4) desakan, (5) persilaan, (6) ajakan, (7) mengizinkan, (8) larangan, (9) harapan, dan (10) anjuran. Sepuluh kalimat tersebut sebenarnya masuk dalam bagian kalimat imperatif permintaan, biasa, suruhan, ajakan dan pemberian izin. Jika dijabarkan menjadi sepuluh kalimat tersebut.

Beberapa pandangan menyatakan definisi dan contoh pada sepuluh jenis kalimat tersebut sesuai dengan macam-macam kalimat imperatif. Ketiga penelitian tersebut memeroleh hasil yang sama dengan penelitian ini. Namun, sebutan kalimat imperatif yang berbeda padahal definisinya sama dan dilihat dari penanda yang digunakan sesuai dengan macam-macam kalimat imperatif yang dikemukakan oleh Ramlan (2005:79).

Kalimat imperatif permintaan memiliki jumlah paling banyak dibandingkan empat jenis kalimat imperatif lainya. Hal ini terjadi karena pada video tutorial skincare Clarin Hayes lebih banyak 
menggunakan

sebuah

permohonan atau disebut dengan

perintah halus atau imperatif

permintaan. Kalimat imperatif

permintaan ditandai dengan

penanda tolong, coba, harap, mohon, jangan, sudilah kiranya, dapatkah seandainya, diminta dengan hormat, dimohon dengan sangat, dan kami mohon agar.

Kalimat imperatif permintaan paling banyak digunakan dalam video tutorial skincare Clarin Hayes karena dalam menyampaikan informasi Clarin Hayes harus sopan dan menunjukkan komunikasi yang baik kepada pendengar. Selain itu, harus mudah dipahami dan bisa diterima dengan baik oleh semua orang, mengingat informasi yang disampaikan melalui media sosial youtube. Berikut data tersebut.

jangan kemana-mana tontonin video tutorial ini sampai habis. (KIP 10)

Berdasarkan teori kalimat imperatif untuk membedakan jenis kalimat imperatif atau perintah dilihat dari penggunaan kalimat, penanda, dan intonasi yang digunakan. Kalimat imperatif atau perintah tidak harus keras bisa juga halus. Kalimat imperatif halus disebut dengan imperatif permintaan yang berarti perintah halus atau meminta dengan sopan. Kalimat imperatif permintaan sama dengan kalimat imperatif larangan. Data diatas menunjukkan kalimat imperatif permintaan atau larangan dilihat dari penanda yang digunakan berupa penanda "jangan" sesuai yang dikemukakan Rahardi (2005:79) yang menyatakan bahwa kalimat imperatif larangan ditandai dengan jangan, dilarang, tidak, tidak boleh.

Sesuai dengan video tutorial skincare

Clarin

Hayes menggunakan penanda "jangan" sebanyak 3 kalimat pada data (KIP10), (KIP 26), dan (KIP 122). Selain itu, Mulyono (2012:58) menyatakan bahwa kalimat imperatif larangan ditandai dengan jangan, dilarang, terlarang, tidak boleh. Penggunaan penanda tidak butuh, harus, diperlukan, coba, dan harap terdapat pada video tutorial skincare Clarin Hayes. Sudiana (2006:112) mengemukakan contoh kalimat imperatif larangan "jangan ambil uang itu ya". Begitupun pada video tutorial skincare Clarin Hayes berikut

J angan lupa like video ini. (KIP 122)

Kutipan tersebut menyatakan perintah untuk memberikan tanda suka pada video milik Clarin Hayes. Begitupun dengan kalimat imperatif biasa yang ditegaskan pada kalimat imperatif yaitu pada penggunaan intonasi dan cenderung menggunakan kata kerja dasar. Hal tersebut sesuai dengan pernyataan Ramlan (2005: 79) bahwa kalimat imperatif biasa memiliki ciri berintonasi keras, didukung dengan kata kerja dasar dan berpartikel -lah, contohnya duduk, lari, dan lain sebagainya.

Video tutorial skincare Clarin Hayes tidak begitu banyak menggunakan imperatif biasa karena informasi yang disampaikan dalam video berupa informasi yang jelas agar mudah dipahami penonton sebagai berikut.

\section{Memasuki usia 50 tahun!} (KIB 101)

Kalimat imperatif pemberian izin diungkapkan dengan intonasi rendah dan sopan. Kalimat imperatif pemberian izin yaitu untuk memberikan izin dengan penanda 
silahkan, biarlah dan beberapa ungkapan lain yang bermakna mempersilakan, seperti diperkenankan, dipersilakan, dan diizinkan. Kalimat pemberian izin sama dengan kalimat persilaan yang ditandai dengan penanda silahkan dan untuk memperhalus bisa digunakan partikel -lah. Beberapa orang mengungkapkan kalimat pemberian izin dengan sebutan kalimat persilaan seperti (Ramlan 2005), Mulyono (2012), dan Sudiana (2006) berbeda dengan Rahardi (2005), dan Chaer (2015) yang menyebut dengan kalimat imperatif pemberian izin.

Dilihat dari definisi dan penanda yang digunakan kedua kalimat tersebut sama. Data berikut menunjukkan kalimat imperatif pemberian izin.

Itu adalah skincare yang diperkenankan untuk para remaja. (KIPI 43)

Kalimat imperatif ajakan terdapat 9 kalimat. Kalimat imperatif ajakan diungkapkan dengan penanda ayo dan intonasi biasa. Kalimat imperatif ajakan berisi penanda misalnya, ayo, biar, coba, mari, harap, hendaknya, dan hendaklah.Kalimat imperatif ajakan subjek boleh ada atau pun dilesapkan.

Ayo, remaja-remaja ni bagi kalian yang mulai menginjak usia 13 tahun hingga 17 tahun atau 18 tahunan. (KIA11)

Kalimat imperatif suruh diungkapkan dengan intonasi biasa dan ada juga dengan intonasi tinggi namun bukan perintah tegas. Kalimat imperatif suruhan digunakan bersama penanda ayo, biar, coba, harap, hendaklah, hendaknya, mohon, silakan, dantolong dan seterusnya. Imperatif ini kadang mirip dengan pernyataan.

Kalian harus udah mulai melakukan eksfoliasi yaitu seminggu sekali. (KIS 63)

Selain itu, berdasarkan hasil penelitian yang dilakukan diperoleh bahwa video tutorial skicare Clarin Hayes memiliki relevansi dengan pembelajaran teks prosedur di SMA berdasarkan isi silabus dan isi video. Syarat dari sebuah teks prosedur dan pembelajaran yang terdapat pada silabus teks prosedur kurikulum 2013 terdapat dalam video tutorial

Skincare Clarin Hayes. Kompetensi dasar "merancang pernyataan umum dan tahapantahapan dalam teks prosedur dengan organisasi yang tepat secara lisan dan tulis" menjadi salah satu bahan kesesuaian video tutorial skincare Clarin Hayes sebagai bahan pembelajaran teks prosedur di SMA. Pembelajaran pada silabus mengajarkan materi, yaitu struktur teks prosedur, konjungsi,penanda wacana, kata ganti, kalimat imperatif, kalimat introgatif, dan kalimat deklaratif. Beberapa hal tersebut ternyata terdapat pada video tutorial skincare Clarin Hayes, yaitu sebagai berikut.

Aku akan membahas skincare yang diperlukan di segala usia mulai dari remaja, 20-an, 30 tahun, 40 tahunan sampai usia 50 tahunan ke atas. Karena di setiap usia ini tu keperluanya berbeda-beda. Jadi video ini bisa menjangkau semua usia.

Kutipan tersebut
merupakan tujuan dari teks
prosedur yang di sampaikan di
awal kalimat yang merupakan hasil


yang akan dicapai. Teks prosedur memiliki struktur seperti yang dikemukakan Setianingsih (2017:6) bahwa teks prosedur memiliki struktur berupa tujuan dan langkah-langkah, tujuan adalah hasil akhir yang akan dicapai, sementara langkah-langkah adalah cara-cara yang ditempuh agar tujuan tercapai dalam teks prosedur.

Struktur teks prosedur juga berisi langkah-langkah yang tidak dapat diubah dan merupakan inti dari sebuah teks prosedur. Langkah-langkah dalam video tutorial skincare Clarin Hayes disampaikan dengan variatif sehingga tidak monoton menggunakan kalimat "selanjutnya" pada setiap tahapan. Penggunaan bahasa yang variatif dapat dijadikan bahan perbandingan dan refrensi dengan topik baru dalam pembelajaran teks prosedur di SMA.

Selain itu, siswa akan memiliki referensi baru atau pengetahuan baru tentang video tutorial dan bahasa yang menarik. Topik video tutorial skincare di youtube termasuk topik baru dan siswa akan mendapatkan pemahaman dan contoh menarik dalam membuat teks prosedur dengan bahasa yang jelas, kreatif dan menarik.

Konjungsi yang digunakan pada video tutorial skincare Clarin Hayes, yaitu jika, apabila, dan seandainya. Konjungsi juga disebut kata sambung atau kata penghubung. Konjungsi merupakan kata yang bertugas untuk menghubungkan dua klausa atau lebih. Penggunaan konjungsi yang menyatakan syarat terdapat pada teks prosedur. Konjungsi yang digunakan, misalnya jika, apabila, atau seandainya. Selain konjungsi yang menyatakan syarat, teks prosedur menggunakan konjungsi 'temporal'. Konjungsi temporal adalah konjungsi yang mengacu pada urutan waktu dan sekaligus menjadi sarana kohesi teks, seperti kemudian atau setelah.

Selain konjungsi, penanda wacana juga terdapat pada video tutorial skincare Clarin Hayes di Youtube. Setianingsih (2017:6) mengemukakan penanda wacana adalah perkataan atau rangkaian perkataan yang berfungsi merangkai pernyataan untuk melanjutkan suatu pernyataan selanjutnya. Kegagalan dalam penggunaan penanda wacana yang tepat akan menyebabkan seluruh wacana tidak mempunyai kesatuan yang lengkap. Penanda wacana dalam kalimat ditandai oleh pertama, lalu, setelah itu, kemudian, selanjutnya, dan akhirnya.

Penggunan penanda wacana terdapat padaVideo tutorial skincare Clarin Hayes namun hanya menggunakan kalimat pertama, selanjutnya, dan lalu pada setiap tahapan. Video tutorial skincare Clarin Hayes menggunakan kata ganti dalam penyampaianya.Kata ganti (pronomina) adalah kata yang digunakan untuk menggantikan benda dan menamai seseorang atau sesuatu secara tidak langsung. Kata ganti yang digunakan pada video tutorial skincare Clarin Hayes, yaitu kita, kalian dan orang.

Kalimat Imperatif, interogatif, dan deklaratif terdapat dalam pembelajaran teks prosedur di SMA begitupun dalam video tutorial skincare Clarin Hayes. Kalimat imperatif adalah kalimat yang mengandung perintah, kalimat imperatif berfungsi untuk meminta atau melarang seseorang melakukan sesuatu. Kalimat imperatif terdapat dalam teks prosedur berjumlah 67 data. Kalimat deklaratif adalah kalimat yang berisi pernyataan. Kalimat deklaratif 
berfungsi memberi informasi atau berita tentang sesuatu. video tutorial skincare Clarin Hayes berisi kalimat deklaratif hampir setengah dari isi video. Namun, kalimat interogatif hanya terdapat sepuluh kalimat pada video. Kalimat interogatif adalah kalimat yang berisi pertanyaan.

\section{SIMPULAN DAN SARAN}

Berdasarkan hasil penelitian dan pembahasan analisis kalimat imperatif dalam video tutorial skincare Clarin Hayes di Youtube, dapat disimpulkan sebagai berikut. Kalimat imperatif dalam video tutorial skincare Clarin Hayes menggunakan lima macam kalimat imperatif. Kalimat imperatif permintaan paling banyak digunakan dalam video tutorial skincare Clarin Hayes. Kalimat imperatif yang digunakan pada video tutorial skincare Clarin Hayes termasuk imperatif halus dan sopan. Kalimat imperatif sama dengan kalimat perintah dan kalimat seru hanya saja sering disebut dengan istilah yang berbeda.

Relevansi video tutorial skincare Clarin Hayes di Youtube pada pembelajaran teks prosedur di SMA. Video tutorial skincare Clarin Hayes memiliki relevansi dalam pembelajaran teks prosedur di SMA. Dilihat dari video tutorial Skincare Clarin Hayes memiliki struktur sesuai dengan pembelajaran teks prosedur. Semua struktur dan kaidah kebahasan dalam teks prosedur terdapat dalam video tutorial skincare Clarin Hayes. Hanya saja, gaya penyampaiannya yang berbeda. Syarat-syarat teks prosedur terdapat dalam video tutorial skincare Clarin Hayes hanya saja menggunakan gaya bahasa nonbaku.
Berdasarkan dari simpulan yang telah dipaparkan maka penulis mengajukan saran-saran berikut.

(1) Kalimat dalam video tutorial skincare Clarin Hayes dapat dijadikan bahan pembelajaran teks prosedur, oleh karena itu disarankan kepada siswa memanfaatkan teknologi sebagai bahan pembelajaran seperti video-video yang diunggah di Youtube.

(2) Kalimat imperatif pada video tutorial skincare Clarin Hayes didominasi dengan bahasa gaul. Oleh karena itu, disarankan kepada guru bahasa indonesia menggunakan bahasa yang benar dengan tidak menyingkat kalimat dan sesuai PUEBI sebagai materi untuk mengajarkan contoh kalimat imperatif .

(3) Penelitian ini menganalisis macam-macam kalimat imperatif yang digunakan dalam video tutorial skincare Clarin Hayes dan relevansinya pada pembelajaran teks prosedur di SMA. Peneliti lain diharapkan dapat melengkapi penelitian mengenai pola kalimat imperatif.

\section{DAFTAR RUJUKAN}

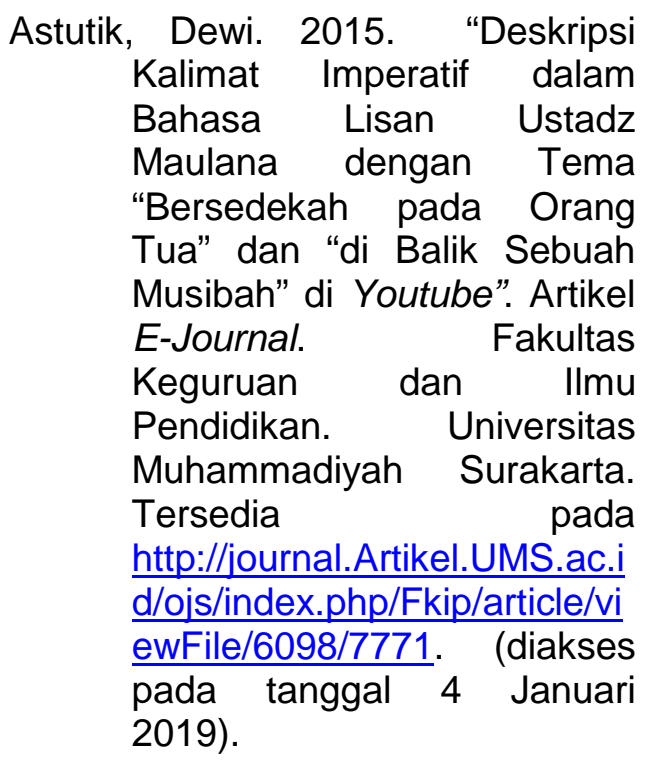


Candra, Mauliddiah Putri. 2015. "Analisis Kalimat Imperatif pada Bahasa Pembina Upacara di SMA Negeri 3 Kota Tanjungpinang". Artikel E-Journal. Jurusan Pendidikan Bahasa dan Sastra Indonesia. Universitas Maritim Raja Ali Haji Tanjungpinang. Tersedia pada

http://jurnal.umrah.ac.id/wpcontent/uploads/gravity form $\mathrm{s} / 1$ ec61c9cb232a03a96d0947c6 478e525e/2015.09/7.-Ejournal.pdf (diakses pada tanggal 4 Januari 2019).

Cangara, Hafied. 2010. Pengantar IImu Komunikasi. Jakarta: Rajawali Press

Chaer,Abdul. 2009. Sintaksis Bahasa Indonesia. Jakarta: Rineka Cipta.

Chaer, Abdul. 2015. Sintaksis Bahasa Indonesia: Pendekatan Proses. Jakarta: Rineka Cipta.

Faizatul,Mufazah Ratu. 2017. Penggunaan Imperatif Bahasa Indonesia oleh Guru Perempuan dalam Kegiatan Pembelajaran di MAN 1 Bandar Lampung Tahun Pelajaran 2016/2017. Skripsi (tidak diterbitkan). Jurusan Pendidikan Bahasa dan Sastra Indonesia. Universitas Lampung. Tersedia pada http://digilib.unila.ac.id/2710 5/3/SKRIPSI\%20Tanpa\%20 BAB\%20PEMBAHASAN.Pd f (diakses pada tanggal 4 Januari 2019)
http://Tekno.tempo.com, diakses pada tanggal 16 Januari 2019.

Mulyono, lyo. 2012. Ihwal Kalimat Bahasa Indonesia dan Problematik Penggunaanya. Bandung: CV Yrama Widya.

Rahardi, Kunjana. 2005. Pragmatik Kesantunan Imperatif Bahasa Indonesia.Jakarta: Erlangga.

Ramlan. 2005. Ilmu Bahasa Indonesia Sintaksis. Yogyakarta: C.V. Karyono.

Setianingsih, Sandra. 2017. Bahasa Indonesia Mata Pelajaran Wajib. Klaten: PT.Intan Pariwara.

Sudiana, I Nyoman. 2006. Sintaksis Bahasa Indonesia. Sidoarjo: Media IImu

Suwandi, Sarwiji. 2008. Semantik Pengantar Kajian Makna.Yogyakarta: MediaPerkasa 